\title{
Spinal Endoscopic Adhesiolysis in the Management of Chronic Low Back Pain: A Preliminary Report of A Randomized, Double- BLIND TRIAL
}

\author{
Laxmaiah Manchikanti, MD, Jose J. Rivera, MD, Vidyasagar Pampati, MSc, Kim S. Damron, RN,
} Carla D. Beyer, RN, BSN, Doris E. Brandon, CST, and Sue R. Wilson, ORT

Epidural adhesiolysis with spinal endoscopy is an emerging interventional pain management technique in managing chronic refractory low back and lower extremity pain. However, there is a lack of significant data demonstrating the effectiveness of spinal endoscopic adhesiolysis.

This randomized, double-blind controlled trial was undertaken to determine the ability of spinal endoscopic adhesiolysis to reduce pain and improve functional and psychological status. The study was performed in an interventional pain management practice, a specialty referral center, in a private practice setting. This trial extended from January 2002 to December 2002. However, only the patients with 6-month follow-up were in cluded. Any relief of less than 6 months was considered as short-term and 6-months or longer was considered as long-term.
All the patients with chronic low back pain of at least 6 months and having failed conservative modalities of management, including fluoroscopically directed epidural steroid injections and percutaneous adhesiolysis, were included. Patient assignment was by randomized selection from all eligible subjects. Two types of interventions were included with Group I serving as the control with endoscopy to the sacral level without adhesiolysis, followed by injection of local anesthetic and steroid. Group II consisted of spinal endoscopy and appropriate adhesiolysis, followed by injection of local anesthetic and steroid. Outcome measures were focused to evaluate and demonstrate a clinically significant difference between the treated patients and those patients randomized to the control group in multiple parameters of pain, functional status, psychological, and behavioral status.
Overall, 13 of 23 patients (57\%) showed significant improvement without adverse events. Based on the definition that less than 6 months of relief is considered as short-term and longer than 6 months is considered as long-term, a significant number of patients obtained long-term relief. The results showed significant improvement in patients undergoing spinal endoscopic adhesiolysis at 1-month, 3-months, and 6-months, compared to baseline measurements, as well as compared to the control group without adhesiolysis.

Spinal endoscopic adhesiolysis with targeted injection of local anesthetic and steroid, is an effective treatment in a significant number of patients without major adverse effects at 6-month follow-up.

Keywords: Persistent low back pain, post-lumbar laminectomy syndrome, epidural fibrosis, spinal endoscopy, myeloscopy
Chronicity in chronic pain is a common problem (1), specifically in low back pain with a prevalence of persistent low back pain ranging from $35 \%$ to $75 \%$ at 12 months after the initial attack (1-11). Kuslich et al (12) identified various tissues capable of transmitting pain in the low back and lower extremity, including intervertebral discs, nerve root dura, facet joints, ligaments, and muscles. Multiple causes described for chronic low back and lower extremity pain include not only disc herniation with neural compression and dysfunction, but also post lum-

From Pain Management Center of Paducah, Paducah, Kentucky. Address Correspondence: Laxmaiah Manchikanti, MD, 2831 Lone Oak Road, Paducah, Kentucky 42003. E-mail: drm@apex.net

Commercial Support: The Myeloscope ${ }^{\circledR}$ Spinal Endoscopy Introducer and Video-Guided Catheter System used in this study were provided by Clarus Medical Systems, Inc. 1000 Boone Ave. N. Suite 100 Golden Valley, MN 55427.

No other external support or funding were received in completion of this study bar laminectomy syndrome, spinal stenosis, vascular compromise, inflammation, and biochemical influences. Post lumbar laminectomy syndrome or pain following operative procedures for lumbar spine is estimated in approximately $5 \%$ to $40 \%$ of patients after surgical intervention (13-18). While there are multiple etiologies responsible for post lumbar laminectomy pain, many have described major causes of continued pain after surgical intervention as epidural fibrosis, facet joint arthritis, and spinal stenosis, among other causes $(13,15,17-20)$.

Post lumbar laminectomy syndrome or failed back surgery syndrome is a term coined by Wilkinson (19) to describe continued pain and disability following surgical intervention with multiple possible explanatory etiologies. Etiologies of failed back surgery syndrome are surgical and non-surgical. Surgical diagnosis included stenosis, internal disc disruption, recurrent disc herniation, or retained disc fragment, spondylolisthesis, etc., whereas non-surgical diagnosis included epidural or intraneural fibrosis, degenerative disc disease, radiculopathy, radicular pain, deconditioning, facet joint pain, sacroiliac joint pain, discitis, and arachnoiditis, etc. Thus, epidural fibrosis is seen as a common phenomenon, which contributes to approximately $60 \%$ of the patients with recurring symptoms in conjunction with instability $(18,20)$. Many possible etiologies of epidural fibrosis include not only surgical intervention and trauma, but also annular tear, hematoma, infection, or intrathecal contrast media.

LaRocca and McNab (21) have demonstrated the invasion of fibrous connective tissue into the postoperative hematoma as a cause of epidural fibrosis. McCarron et al (22) investigated the irritative effect of material from the nucleus pulposus upon the dural sac, adjacent nerve roots, and nerve root sleeves independent of the influence of direct compres- 
sion upon these structures. McCarron (23) further explored epidural fibrosis in an experimental model in adult Montreal dogs. He reported an inflammatory reaction in the spinal cord sections taken from dogs sacrificed after the initial injection of homogenized nucleus pulposus, whereas, the spinal cord was grossly normal after the initial injection of normal saline. Cooper et al (24) reported periradicular fibrosis and vascular abnormalities occurring with herniated intervertebral discs. Hoyland et al (25), in a cadaveric study, found significant pathological changes within and around the nerve root complex, including peri- and intraneural fibrosis, edema of nerve roots, and focal demyelination proposing that venous obstruction may be an important pathogenic mechanism in the development of perineural and intraneural fibrosis. In addition, epidural adhesions were also demonstrated in cadavers with lumbar disc herniation with $40 \%$ of cadavers showing adhesions at $\mathrm{L} 4 / 5$ level, $36 \%$ at L5/S1 level, and in $16 \%$ at $\mathrm{L} 3 / 4$ level (26). It was also shown that perineural fibrosis, which interferes with cerebrospinal fluid-mediated nutrition, can render nerve roots hyperesthetic and hypersensitive to compression forces $(27,28)$. Songer et al (29) showed that postoperative scar tissue renders the nerve susceptible to injury.

Even though epidural fibrosis is commonly seen in patients with recurring symptoms in conjunction with instability and post lumbar laminectomy syndrome (13-15, 17-20, 30-36), its causative role in chronic low back pain has been questioned $(14,15,17,30,33,34)$. Ross et al (36), in a study of the relationship between epidural scar and radicular pain, evaluated by magnetic resonance imaging (MRI) after lumbar laminectomy, showed that subjects with extensive peridural scarring were 3.2 times more likely to experience radicular pain.

Epidural injection of corticosteroids is one of the commonly used interventions in managing chronic low back and lower extremity pain. Manchikanti et al (37), in an evidence-based review of the effectiveness of epidural steroids showed that while overall evidence was moderate for long-term relief, for caudal epidural steroids, there was no significant evidence provided with either interlaminar epidural steroid injections or transforaminal epidural steroid injections. However, this review also showed that 2 of the stud- ies which exclusively studied post lumbar laminectomy syndrome $(38,39)$ and an additional two studies which studied spinal stenosis with caudal epidural (40) and interlaminar epidural (41) yielded contradictory results. In fact, in a 2002 review (14) describing the role of decompressive surgery in managing chronic pain of spinal origin after lumbar surgery, authors commented that, at the time of writing of the article, no form of surgical treatment or adhesion lysis procedure for this diagnosis has proven to be safe and effective. Thus, a conservative alternative to surgical intervention, percutaneous epidural adhesiolysis emerged. The purpose of percutaneous epidural adhesiolysis was to eliminate the deleterious effects of a scar which can physically prevent the targeted application of drugs to nerve or other tissues, and to assure delivery of high concentration of injected drugs to the target areas (17). The clinical effectiveness of percutaneous adhesiolysis evaluated in two randomized controlled trials $(42,43)$, and multiple retrospective evaluations (44-48) showed that the effectiveness of percutaneous adhesiolysis (37), is moderate for short-term and long-term relief with repeat interventions. Thus, a significant number of patients continue to suffer with persistent low back and lower extremity pain in spite of epidural injections and percutaneous epidural adhesiolysis.

Spinal endoscopy with epidural adhesiolysis is an interventional pain management technique which emerged during the 1990s $(20,49,50)$. While the goal of percutaneous lysis of epidural adhesions was to assure delivery of high concentration of injected drugs to the target areas, spinal endoscopic adhesiolysis is to provide a three-dimensional view by spinal epiduroscopy or spinal endoscopy with facilitation of direct application of corticosteroid into the target area after adhesiolysis. While spinal endoscopy with adhesiolysis is an emerging technique, its clinical effectiveness was evaluated in two prospective evaluations $(51,52)$ and four retrospective trials (53-56), and multiple case reports. The evidence-based evaluation (37), defining relief of less than 6 months was short-term and greater than 6 months of relief as long-term showed moderate evidence for short-term relief and limited evidence for long-term relief. Understandably, many physicians believe that there is no evidence vindicating spinal endoscopy with epidural adhesiolysis in the management of chronic intractable low back and lower extremity pain.

Hence, this randomized, doubleblind, controlled evaluation of the effectiveness of spinal endoscopy with lumbar epidural adhesiolysis in the management of chronic low back and lower extremity pain was undertaken in patients non-responsive to not only fluoroscopically directed epidural steroid injections, but also percutaneous adhesiolysis and hypertonic saline neurolysis.

\section{Methods}

This randomized, double-blind controlled evaluation of the effectiveness of percutaneous lumbar epidural adhesiolysis and hypertonic saline neurolysis was undertaken in an interventional pain management practice, a specialty referral center, in a private practice setting. The study protocol was approved by the Institutional Review Board as a single center, prospective, controlled, double-blind, randomized controlled trial. Group I consisted of a control group with introduction of spinal endoscope up to S3 level with injection of local anesthetic and steroid. Group II consisted of patients undergoing spinal endoscopic adhesiolysis, with injection of local anesthetic and steroid.

\section{Inclusion and Exclusion Criteria}

Participants in this study were identified from the existing patient load of the interventional pain management practice. In addition, new patients, eligible for enrollment, were identified from the program as they started the program. Inclusion criteria included patients between 18 and 65 years of age, with a history of chronic low back pain of at least 6 months, having shown absence of facet joint pain by controlled comparative local anesthetic blocks, having failed to respond to conservative treatment including fluoroscopically directed epidural injections, having failed to respond to percutaneous adhesiolysis with hypertonic saline neurolysis, and willingness to participate in the clinical trial. Exclusion criteria included cauda equina syndrome, compressive radiculopathy, surgical intervention in previous 6 months, opioid addiction, uncontrolled major depression or psychiatric disorders, uncontrolled or acute medical illnesses, chronic severe conditions that could interfere with the interpretations of the outcome assessments for 
pain and bodily function, pregnant or lactating women, history of adverse reaction to local anesthetic or steroids, patients unable to understand the informed consent and protocol, or patients unable to be positioned in prone position to perform the procedure.

\section{Evaluation}

All the patients were provided with the approved protocol and the informed consent approved by the Institutional Review Board for this study. The informed consent showed the details of randomization, interventions, blinding and unblinding, and screening and follow-up evaluations.

Screening evaluation included demographic data, medical/surgical history with coexisting diseases, radiographic investigations, physical examination, psychological evaluation with Pain Patient Profile (P-3), visual analog scale (VAS) pain scores, work status, Oswestry Disability Index, and lumbar spine range of motion.

\section{Procedure}

All the patients in both groups were provided identical preparation. All procedures were performed under fluoroscopy in an ambulatory surgery center in sterile operating rooms by one physician. The procedure included appropriate preparation with intravenous access, antibiotic administration, sterile preparation, and appropriate sedation with small doses of midazolam and fentanyl. Access to the epidural space was obtained with a RK® needle. An epidurogram was obtained identifying filling defects and/or epidural fibrosis. Adhesiolysis was carried out in Group II utilizing the Myeloscope ${ }^{\circledR}$ spinal endoscopic video-guided catheter system and introducer system, with final positioning of the fiberoptic endoscope on the side and level of the defect and the source of pain with an additional injection of contrast to identify successful adhesiolysis, followed by injection of local anesthetic and steroid.

In Group I, after the initial epidurography, a $0.9 \mathrm{~mm}$ guidewire was inserted through the needle, which was advanced under fluoroscopic guidance to S3 level. Following this, a $2-\mathrm{mm} \times 17.8-\mathrm{cm}$ dilator with catheter (sheath) was passed over the guidewire again up to S3. Once the catheter was advanced to the tip of the guidewire, the wire was removed. At this time, a $0.8-\mathrm{mm}$ fiberoptic spinal endoscop- ic video guided system was introduced into the catheter through the valve and was advanced until the tip was positioned at the distal end of the catheter through the valve, as determined by video and fluoroscopic images not to exceed S3. Following this, $10 \mathrm{~mL}$ of $1 \%$ lidocaine and 6 $\mathrm{mg}$ to $12 \mathrm{mg}$ of Celestone or $40 \mathrm{mg}$ to 80 $\mathrm{mg}$ of methylprednisolone were injected through the myeloscope. Following this, the scope was removed and appropriate sterile Bioclusive dressing was applied.

In Group II, a 0.9-mm guidewire was inserted through the needle, which was advanced under fluoroscopic guidance to the level of suspected pathology, followed by a small incision and advancement of a $2-\mathrm{mm} \times 17.8-\mathrm{cm}$ dilator with catheter (sheath) over the guidewire. Once the catheter was advanced to the tip of the guidewire, the wire was removed. Following this, a $0.8-\mathrm{mm}$ fiberoptic spinal endoscopic video-guided system was introduced into the catheter through the valve and was advanced until the tip was positioned at the distal end of the catheter, as determined by video and fluoroscopic images. In conjunction with gentle irrigation using normal saline, the catheter and fiberoptic myeloscope were manipulated and rotated in multiple directions, with visualization of the nerve roots at various levels. Gentle irrigation was carried out by slow, controlled infusion. Adhesiolysis and decompression were carried out by distension of the epidural space with normal saline, and by mechanical means utilizing fiberoptic endoscope. Confirmation was accomplished with the injection of non-ionic contrast material and an epidurogram was performed on at least $2 \mathrm{oc}-$ casions. Following completion of the procedure, generally, lidocaine $1 \%$, preservative free, mixed with $6 \mathrm{mg}$ to $12 \mathrm{mg}$ of betamethasone acetate and $40 \mathrm{mg}$ to $80 \mathrm{mg}$ of methylprednisolone was injected in each case after assuring that there was no evidence of subarachnoid leakage of contrast. If pathology was determined to be at multiple levels, the procedure was carried out at multiple levels and the injectate was injected in divided doses. If there was a question of subarachnoid leakage of the contrast, a Racz catheter was passed into the epidural space, and mixture of local anesthetic was injected very slowly in incremental doses, followed by injection of the steroid if satisfactory follow-up was obtained without any subarachnoid blockade. Following the injection of local anesthetic and steroid, the scope was removed and appropriate sterile Bioclusive dressing was applied.

The patient was transported to the recovery room and was very closely monitored for any potential complications or side effects.

\section{Outcomes Assessment}

Objectives of this evaluation were to demonstrate significant treatment outcomes among the patients undergoing spinal endoscopic adhesiolysis compared to the control group. The primary endpoints of the investigation were to demonstrate a clinically significant difference in the spinal endoscopic adhesiolysis group compared with patients randomized to the control group at 1-month, 3months, and 6-months post-treatment in the VAS pain scale, Oswestry Disability Index, work status, concomitant medication, range of motion measurement, and P-3. Secondary endpoint included the assessment of adverse events.

VAS was measured on a $10 \mathrm{~cm}$ scale. P-3 psychological evaluation and Oswestry Disability Index were assessed by administration of standard questionnaire. The Oswestry Disability Index was calculated with a total score (maximum 50), divided by number of items answered ( $\max -$ imum 10). Range of motion was evaluated by a certified physical therapist blinded to type of treatment. Non-physiological symptoms and signs were evaluated by an experienced physician, per the criteria described by Waddell et al $(57,58)$.

Narcotic intake was determined as none, mild, moderate, or heavy based on the dosage, frequency and schedule of the drug. Intake of Schedule IV narcotics, i.e., propoxyphene napsylate, pentazocine hydrochloride, tramadol hydrochloride up to a maximum of 4 times, or hydrocodone twice or less per day, was considered as mild; intake of Schedule III narcotics, i.e., hydrocodone, up to 4 times per day was considered as moderate; and intake of Schedule II narcotics, i.e., oxycodone, morphine, meperidine, transdermal fentanyl, and methadone, in any dosage was considered as heavy.

Employment and work status (employed, unemployed, housewife, disabled, and retired) were determined from the pre-treatment and post-treatment work status. Only employed and unemployed patients were considered to be eligible for employment, whereas disabled patients 
and patients over 65 were considered not employable.

Duration of relief was judged to be short-term if the relief was less than 6 months; whereas if the relief lasted for 6 months, it was considered as long-term.

\section{Study Design}

Randomization was 2:3 with 2 patients randomized to the control group (Group I), for every 3 patients randomized to spinal endoscopic adhesiolysis or Group II. The $\alpha$ equals 0.05 level. This sample size was determined to attract patients into the trial, to induce the belief that they would have higher chances of being in the treatment group, rather than the control group.

All the eligible patients willing to participate in the trial were randomized 2: 3 into Groups I and II respectively. Randomization was assigned in blocks of 20 to ensure relative balance in treatment assignment throughout the trial. Randomization was performed by computer generated random allocation sequence. There were no restrictions.
The random allocation was concealed until the intervention. Random allocation was provided in a sealed envelope to one of the investigators of the study who was not involved with subsequent follow-up of the patient. The envelope was opened in each case after RK needle was inserted into the caudal epidural space. Randomization was not revealed to the personnel in the recovery room or the reviewing physician.

Randomization was generated by a biostatistician without knowledge of the patients after assigning consecutive numbers. Patients were assigned to 1 of the 2 groups based on the computer generated random allocation sequence.

All the patients, nursing personnel participating in the care except the personnel involved in the intervention, and all those assessing the outcomes were blinded to Group assignment. Blinding was successful as none of the personnel aware of the Group assignment were involved in subsequent assessment until unblinding was carried out. Further, 6 patients in Group I, believed that they re- ceived spinal endoscopic adhesiolysis and 8 patients in spinal endoscopy with adhesiolysis in group II believed they received control treatment. However, it appeared that patient belief was not based on pain relief. The evaluating physician was also unable to correctly assess the Group assignment in $60 \%$ of cases.

The patients were unblinded if they requested to be unblinded or treatment was a failure at 3 months. All other patients were unblinded at 6 months. $\mathrm{Pa}$ tients were also given an option to discontinue or to withdraw from the study for various reasons. They were considered to be withdrawn if follow-up was lost.

Data were recorded on a database using Microsoft ${ }^{\circledR}$ Access $^{\circledR}$. The SPSS Version 9.0 statistical package was used to generate the descriptive tables. Differences in proportions were tested by using the chisquared test. Fischer's exact test was used wherever the expected value was less than five. Student's t test was used to test mean differences between groups. Paired t test was used to compare the pre- and posttreatment. Results were considered sta-

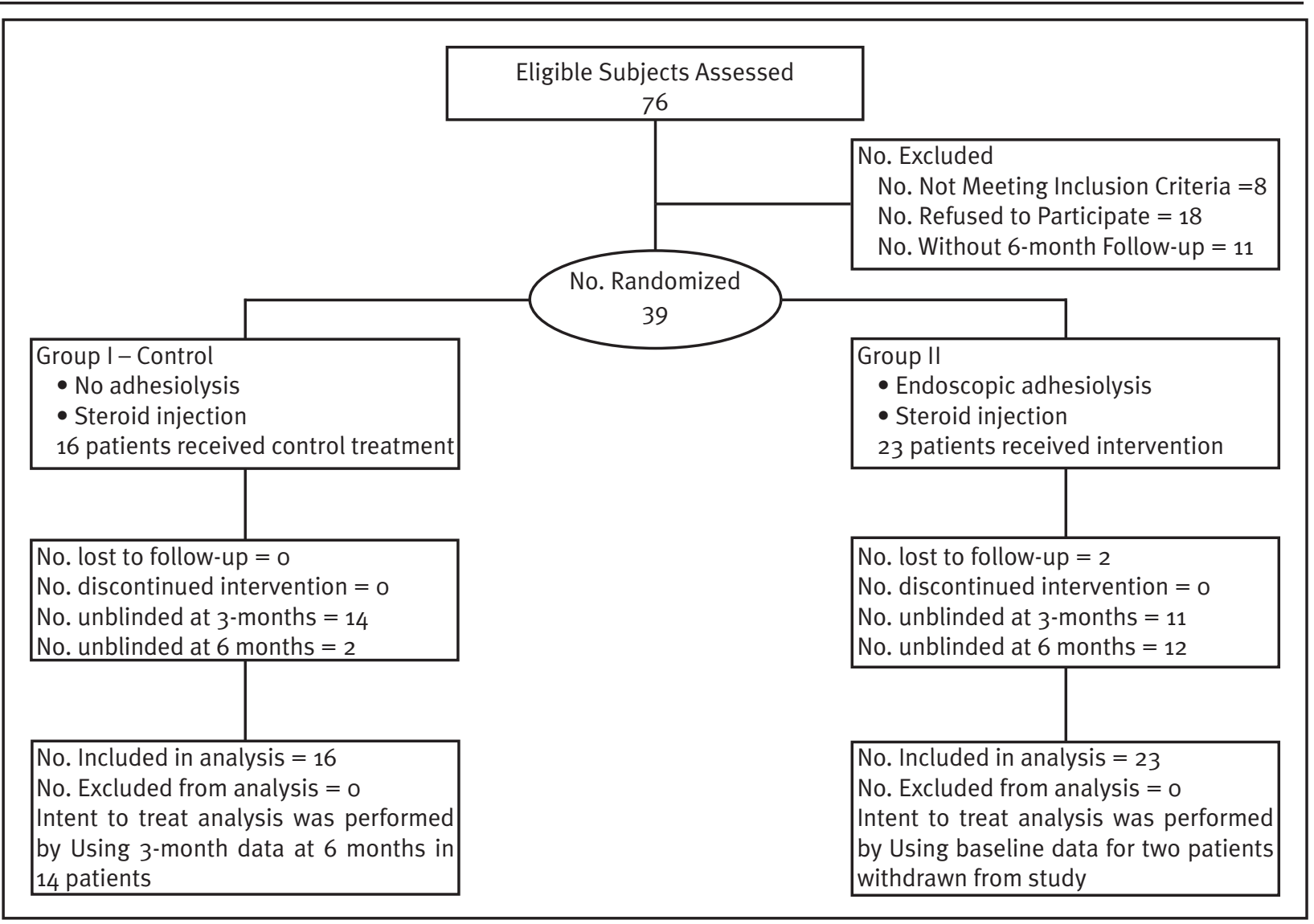

Fig. 1. Trial Flow Diagram 
tistically significant if the $P$ value was less than 0.05 .

\section{REsULTS}

\section{Trial Flow Characteristics}

A trial flow diagram is illustrated in Figure 1. Recruitment lasted from January 1, 2002 to December 31, 2002. Thirty-nine patients met 6-month follow-up criteria. Two patients were lost to follow up and were withdrawn from the study in Group II. One patient experienced no improvement, withdrew from the study and underwent further surgical intervention. The second patient in Group II failed to obtain any significant relief, was withdrawn from the study, and refused further follow-up. In Group I, intent to treat analysis was performed by using 3-month data at 6 months in 14 of the 16 patients. In Group II, intent to treat analysis was performed by using baseline data at all follow-up periods.

\section{Demographic Characteristics}

Table 1 illustrates the demographic characteristics of patients who were followed through 6 months. There were no significant differences noted between the groups with age, gender, height, weight, duration of pain, or the history of previous surgery.

\section{Structural Abnormalities}

Structural abnormalities based on MRI findings as per the reading of the radiologist are included in Table 2. The majority of the patients presented with moderate or extensive epidural fibrosis. There were no differences noted among the groups.

Table 1. Demographic Characteristics

\begin{tabular}{|c|c|c|c|}
\hline & & Group I & Group II \\
\hline \multicolumn{2}{|l|}{ Number of patients } & 16 & 23 \\
\hline Age (Years) & Mean \pm SD & $49 \pm 10$ & $51 \pm 11$ \\
\hline \multirow{2}{*}{ Gender } & Male & $37 \%$ & $26 \%$ \\
\hline & Female & $63 \%$ & $74 \%$ \\
\hline Height (Inches) & Mean \pm SD & $66 \pm 4.2$ & $66 \pm 3.4$ \\
\hline Weight (Lbs) & Mean \pm SD & $177 \pm 45$ & $167 \pm 36$ \\
\hline Duration of pain (months) & Mean \pm SD & $120 \pm 87$ & $111 \pm 70$ \\
\hline \multirow{2}{*}{ Onset of the pain } & Traumatic & $31 \%$ & $30 \%$ \\
\hline & Non-traumatic & $69 \%$ & $70 \%$ \\
\hline \multicolumn{2}{|l|}{ Previous Surgery } & $63 \%$ & $70 \%$ \\
\hline
\end{tabular}

Table 2. Structural abnormalities based on MRI findings as per the Radiologist

\begin{tabular}{|l|c|c|}
\hline & $\begin{array}{c}\text { Group I } \\
\mathbf{n = 1 6}\end{array}$ & $\begin{array}{c}\text { Group II } \\
\mathbf{n = 2 3}\end{array}$ \\
\hline Epidural Fibrosis* & & \\
\hline Mild & $1(6 \%)$ & $3(13 \%)$ \\
\hline Moderate & $3(19 \%)$ & $5(22 \%)$ \\
\hline Extensive & $5(31 \%)$ & $9(39 \%)$ \\
\hline DISC displacement* & & \\
\hline Herniation & $2(12 \%)$ & $2(9 \%)$ \\
\hline Bulging & $1(6 \%)$ & $1(4 \%)$ \\
\hline Severe Degeneration & $1(6 \%)$ & $1(4 \%)$ \\
\hline Severe Spinal Stenosis* & $1(6 \%)$ & $1(4 \%)$ \\
\hline
\end{tabular}

* These categories were not mutually exclusive. Some patients had more than one pathology, some had none. Therefore, these totals donot $=n$

Pain and Functional Outcome Measures Table 3 illustrates pain and functional measures, which included VAS, Oswestry Disability Index, and range of motion measurements. There were no significant differences noted with baseline measurements between the two groups. However, significant differences were noted with pain relief, and range of motion between Group I and Group II. There was also improvement in VAS pain rating, Oswestry Disability Index, and range of motion from baseline to 1 month, 3 months, and 6 months. There were no improvements noted in Group I from baseline to 1 -month, 3-months, and 6-months in

Table 3. Analysis of physical and functional outcome measurements

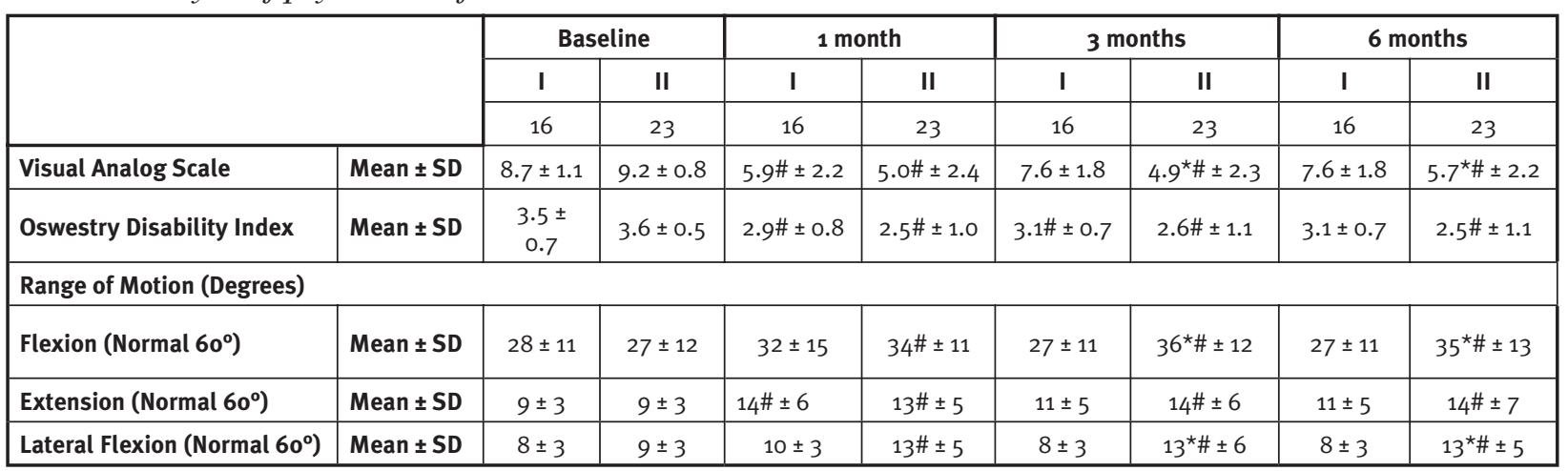

* Indicates significant difference between Group I and Group II at the time of evaluation

\# Indicates significant difference with Baseline values within the Group at various points of evaluation 


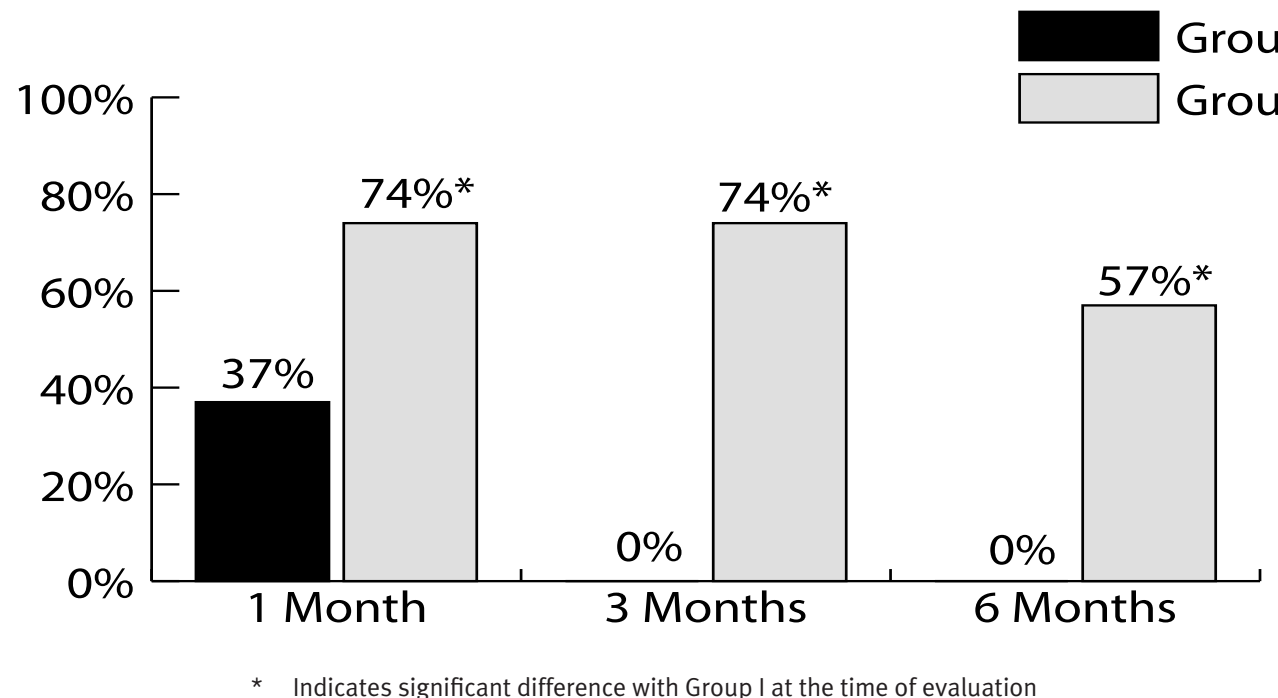

Fig. 2. Proportion of patients with significant relief ( $\geq 50 \%)$ at 1 month, 3 months, and 6 months

most parameters.

Table 4 illustrates duration of significant pain relief $(\geq 50 \%)$ in weeks with first procedures for successful patients and all patients. Patients in Group II experienced significantly longer relief compared to Group I.

Table 4. Duration of significant pain relief ( $\geq 50 \%)$ in weeks (Mean $\pm S D)$ with first procedure

\begin{tabular}{|l|c|c|}
\hline & All Patients & Successful Patients \\
\hline Group I & $\begin{array}{c}3.6 \pm 3 \cdot 3 \\
(16)\end{array}$ & $\begin{array}{c}6.8 \pm 2.6 \\
(6)\end{array}$ \\
\hline Group II & $\begin{array}{c}24.3^{*} \pm 18.5 \\
(23)\end{array}$ & $\begin{array}{c}31.7^{\star} \pm 15.3 \\
(17)\end{array}$ \\
\hline
\end{tabular}

* Indicates significant difference with Group I ( )Indicates number of patients
Figure 2 shows the proportion of patients with significant relief $(\geq 50 \%)$ at 1 month, 3-months, and 6-months. None of the patients in Group I, obtained significant pain relief for 3 months, whereas in Group II, 13 of 23 patients (57\%) obtained significant relief at 6 months.

Table 5. Analysis of psychological and behavioral outcome measurements

\begin{tabular}{|c|c|c|c|c|c|c|c|c|c|}
\hline & & \multicolumn{2}{|c|}{ Baseline } & \multicolumn{2}{|c|}{1 month } & \multicolumn{2}{|c|}{3 months } & \multicolumn{2}{|c|}{6 months } \\
\hline & & I & II & $I$ & II & I & II & $I$ & II \\
\hline & & 16 & 23 & 16 & 23 & 16 & 23 & 16 & 23 \\
\hline \multirow{2}{*}{ Depression } & Diagnosis & $10(63 \%)$ & 17 (74\%) & 6 (38\%) & $5 \#(22 \%)$ & 7 (44\%) & 10\# (44\%) & 7 (44\%) & $11(48 \%)$ \\
\hline & Score & 58 & 58\# & $53 \#$ & $50 \#$ & $52 \#$ & $54 \#$ & 52\# & $54 \#$ \\
\hline \multirow{2}{*}{ Anxiety } & Diagnosis & $8(50 \%)$ & $13(57 \%)$ & 6 (38\%) & 6\# (26\%) & $5(31 \%)$ & $10(44 \%)$ & $5(31 \%)$ & $9(39 \%)$ \\
\hline & Score & 56 & $56 \#$ & $53 \#$ & 50\# & 49\# & $53 \#$ & 49\# & $50 \#$ \\
\hline \multirow{2}{*}{ Somatization } & Diagnosis & $12(75 \%)$ & $18(78 \%)$ & $8(50 \%)$ & $8 \#(35 \%)$ & 7 (44\%) & 10\# (44\%) & 7 (44\%) & $10 \#(44 \%)$ \\
\hline & Score & 57 & $60 \#$ & $56 \#$ & 51\# & 55 & $53 \#$ & 55 & $54 \#$ \\
\hline \multicolumn{2}{|c|}{$\begin{array}{l}\text { Non-physiological } \\
\text { symptoms }\end{array}$} & 9 (56\%) & $13(57 \%)$ & $9(56 \%)$ & $11(48 \%)$ & $9(56 \%)$ & $8(35 \%)$ & $9(56 \%)$ & 7 (30\%) \\
\hline \multicolumn{2}{|c|}{ Non-physiological signs } & $10(63 \%)$ & $11(48 \%)$ & $10(63 \%)$ & $11(48 \%)$ & $10(63 \%)$ & $7^{\star}(30 \%)$ & $10(63 \%)$ & $7^{\star}(30 \%)$ \\
\hline
\end{tabular}

* Indicates significant difference with Group I at the time of evaluation

\# Indicates significant difference with baseline values within the Group at various points of evaluation 
Table 6. Analysis of narcotic intake

\begin{tabular}{|l|c|c|c|c|c|c|c|c|}
\hline \multirow{2}{*}{} & \multicolumn{2}{|c|}{ Baseline } & \multicolumn{2}{c|}{ 1 month } & \multicolumn{2}{c|}{ 3 months } & \multicolumn{2}{c|}{$\mathbf{6}$ months } \\
\cline { 2 - 10 } & I & II & I & II & I & II & I & II \\
\hline None & 16 & 23 & 16 & 23 & 16 & 23 & 16 & 23 \\
\hline Mild & $0(0 \%)$ & $0(0 \%)$ & $0(0 \%)$ & $2(9 \%)$ & $0(0 \%)$ & $2(9 \%)$ & $0(0 \%)$ & $2(9 \%)$ \\
\hline Moderate & $1(6 \%)$ & $1(4 \%)$ & $2(12 \%)$ & $4(17 \%)$ & $2(12 \%)$ & $4(17 \%)$ & $1(6 \%)$ & $4(14 \%)$ \\
\hline Significant & $7(44 \%)$ & $8(35 \%)$ & $8(50 \%)$ & $4(17 \%)$ & $8(50 \%)$ & $5(22 \%)$ & $8(50 \%)$ & $5(22 \%)$ \\
\hline
\end{tabular}

as described. Narcotic intake was somewhat less at 1, 3, and 6 months in Group II compared to the baseline intake (Table 6).

Employment status was also evaluated as illustrated in Table 7. The majority of the patients were in non-employable category. At the end of 6 months, unemployment remained the same in Groups I and II, however, employment was increased to $17 \%$ in Group II compared to $4 \%$ at baseline.

\section{Adverse Events}

There was one case of subarachnoid block in Group II, which was identified after completion of the procedure and injection of local anesthetic and steroid. There were no other adverse events noted.

\section{DISCUSSION}

In this randomized, double-blind, controlled evaluation, we have demonstrated that a significant proportion of patients, 13 of 23 (57\%) in Group II with spinal endoscopic adhesiolysis and targeted delivery of steroid and local anesthetic, obtained significant relief immediately after the treatment, at 1 month, at 3 months, and at 6 months. Significant pain relief $(>50 \%)$ was also associated with improvement in Oswestry Disability Index, range of motion, and psychological status compared to baseline measurements. The improvement was also significant in Group II compared to Group I in multiple parameters. Further, significant improvement was noted in psychological and behavioral outcome measures. This study was randomized and double-blinded. The disadvantages include un-blinding in some patients at 3-months if the patient desired, instead of 6-months in all patients. However, considering the difficulties with recruiting patients to a double-blind trial, this was the only effective means to convince patients that they could be provided with treatment rather than suffer for 6 months or a year. Our randomization was also different instead of being 1:1, it was 2:3. This randomization process was selected to convince the patients to be enrolled in the study as they would have a higher chance of being included in a treatment group, rather than the control group. The statistical validity was maintained throughout the study and the intent to treat analysis was incorporated.

It is imperative to understand that patients included in this study represented a subset of patients who have not only failed other conservative modalities of management, including fluoroscopically directed epidural steroid injections, but also failed percutaneous adhesiolysis. Thus, significant pain relief greater than $50 \%$ with improvement in physical, functional, psychological, and behavioral status represents progress in the management of refractory, persistent chronic low back pain.
Manchikanti et al (37) reviewed the results of published reports of spinal endoscopy with pre-established criteria. Among these evaluations, Geurts et al (51) studied 20 patients with chronic low back pain. This study focused on the role of epiduroscopy and its value in the diagnosis of spinal root pathology. They reported that in sciatica, adhesions unreported by MRI can be identified apart from targeted epidural medication, administered near the compromised spinal nerve, resulting in substantial and prolonged pain relief. In contrast, our study did not focus on the diagnostic value of epiduroscopy. The diagnostic value of epiduroscopy has not been shown to be of any significant importance in either prospective or retrospective evaluations. Of the 20 patients they studied, they reported adhesions in 19 patients with inflamed nerve root without adhesions in another patient. They correlated the MRI findings of extensive adhesions in 11 patients. Further, in 8 of the remaining 9 patients, in whom no abnormalities were detected on MRI, adhesions were found around the suspected painful nerve root. Six of these patients had had no prior low back surgery. They also reported that in 6 of the 20 patients, active signs of root inflammation were seen, in 5 cases combined with adhesions. While we found adhesions in all the patients, we have not found any active signs of root inflammation as reported by Geurts et al (51). They report-

Table 7. Employment status

\begin{tabular}{|l|c|c|c|c|c|c|c|c|}
\hline & \multicolumn{2}{|c|}{ Baseline } & \multicolumn{2}{c|}{ 1 month } & \multicolumn{2}{c|}{ 3 months } & \multicolumn{2}{c|}{6 months } \\
\cline { 2 - 10 } & I & II & I & II & I & II & I & II \\
\hline & 16 & 23 & 16 & 23 & 16 & 23 & 16 & 23 \\
\hline Employed & $1(6 \%)$ & $1(4 \%)$ & $1(6 \%)$ & $2(9 \%)$ & $1(6 \%)$ & $4(17 \%)$ & $1(6 \%)$ & $4(17 \%)$ \\
\hline Unemployed & $1(6 \%)$ & $1(4 \%)$ & $1(6 \%)$ & $1(4 \%)$ & $1(6 \%)$ & $1(4 \%)$ & $1(6 \%)$ & $1(4 \%)$ \\
\hline Housewife & $2(13 \%)$ & $1(4 \%)$ & $2(13 \%)$ & $1(4 \%)$ & $2(13 \%)$ & $1(4 \%)$ & $2(13 \%)$ & $1(4 \%)$ \\
\hline Disabled & $11(69 \%)$ & $18(79 \%)$ & $11(69 \%)$ & $17(74 \%)$ & $11(69 \%)$ & $15(65 \%)$ & $11(69 \%)$ & $15(65 \%)$ \\
\hline Over 65 yrs of age & $1(6 \%)$ & $2(9 \%)$ & $1(6 \%)$ & $2(9 \%)$ & $1(6 \%)$ & $2(9 \%)$ & $1(6 \%)$ & $2(9 \%)$ \\
\hline
\end{tabular}


ed that VAS scores preoperatively at 3months follow-up showed that treatment led to a significant pain reduction. However, they also rated only 7 patients as successful, as measured by VAS at 12-months follow-up. They also followed only $7 \mathrm{pa}-$ tients through 12-month period and used, loss of follow-up analysis, in which every missing VAS score was replaced by the most recently measured VAS score. This would have produced unreliable results as most patients showed improvement at 3-months. However, they failed to show similar improvements at a later date. Some patients at 3 months in fact showed a VAS score of 3. Thus, this analysis appears to be flawed. Overall, they reported greater than $50 \%$ reduction in pain in $40 \%$ of the patients at 3 -months, $35 \%$ at 6-months, and $35 \%$ at 9 -months and 12 months. With regards to the pain relief, the results of this randomized, doubleblind clinical trial are superior with 57\% of the patients showing improvement not only in Visual Analog Pain Scale, but also in various other measures at 6 months.

Richardson et al (52) reported results in 38 patients, with 19 patients with failed back surgery syndrome. They also reported diagnostic value with identification of pain generator in 34 of 34 patients. They reported dense adhesions in $41 \%$ of the patients. In this non-controlled, prospective study of 38 patients, they reported significant improvement based on Visual Analog Scale and functional abilities. However, the data was not available with regards to proportion of patients with sustained relief at various time periods. Finally, Manchikanti et al $(53,55)$ in two different studies, reported $75 \%$ relief at 3-months, $40 \%$ at 6-months, and $22 \%$ at 12 -months in post lumbar laminectomy patients; and in $52 \%$ of the patients at 3 -months, $21 \%$ of the patients at 6 -months, and $7 \%$ of the patients after 12 months in a heterogenous group of patients, which included both post laminectomy and non-laminectomy patients, however, non-responsive to fluoroscopically directed epidural steroid injections and percutaneous adhesiolysis.

Thus, our results of this randomized, double-blind controlled trial are superior to a prospective observational study (51), a prospective case series (52), and two retrospective evaluations $(53,55)$.

\section{CONCLUSION}

This study showed that spinal endoscopic adhesiolysis reduces pain and improves the physical, functional, psychological, and behavioral status in a significant number of patients, without adverse effects. The results of this randomized, double-blind controlled trial were superior to previously published prospective observational studies, prospective case series, and retrospective evaluations.

\section{Author Affiliation:}

Laxmaiah Manchikanti, MD

Medical Director

Pain Management Center of Paducah

2831 Lone Oak Road

Paducah, Kentucky 42003

E-mail: drm@apex.net

\section{Jose J. Rivera, MD}

Interventional Pain Physician

Pain Management Center of Paducah

2831 Lone Oak Road

Paducah, Kentucky 42003

E-mail: Jose@thepainmd.com

\section{Vidyasagar Pampati, MSc}

Statistician

Pain Management Center of Paducah 2831 Lone Oak Road,

Paducah, Kentucky 42003

E-mail: sagar@painmd.com

Kim A. Cash, RT

Clinical Coordinator

Ambulatory Surgery Center

2831 Lone Oak Road

Paducah, Kentucky 42003

\section{Carla D. Beyer, RN, BSN}

Clinical Coordinator,

Ambulatory Surgery Center

2831 Lone Oak Road

Paducah, Kentucky 42003

Doris E. Brandon, CST

Surgical Technologist

Ambulatory Surgery Center

2831 Lone Oak Road

Paducah, Kentucky 42003

\section{Sue R. Wilson, ORT}

Surgical Technologist

Ambulatory Surgery Center

2831 Lone Oak Road

Paducah, Kentucky 42003

\section{REFERENCES}

1. Elliott AM, Smith BH, Hannaford PC et al. The course of chronic pain in the community: Results of a 4-year follow-up study. Pain 2002; 99:299-307.

2. Waxman R, Tennant A, Helliwell P. A prospective follow up study of low back pain in the community. Spine 2000; 25:2085-2090.

3. van den Hoogen HJM, Koes BW, Deville W et al. The prognosis of low back pain in general practice. Spine 1997; 22:1515-1521.

4. Croft PR, Papageorgiou AC, Thomas E et al. Short-term physical risk factors for new episodes of low back pain. Prospective evidence from the South Manchester Back Pain Study. Spine 1999; 24:15561561.

5. Carey TS, Garrett JM, Jackman A et al. Recurrence and care seeking after acute back pain. Results of a long-term followup study. Medical Care 1999; 37:157-164.

6. Miedema HS, Chorus AM, Wevers CW et al. Chronicity of back problems during working life. Spine 1998; 23:2021-2028.

7. Thomas E, Silman AJ, Croft PR et al. Predicting who develops chronic low back pain in primary care. A prospective study. Brit Med J 1999; 318:1662-1667.

8. Wahlgren DR, Atkinson JH, Epping-Jordan JE et al. One-year follow up of first onset low back pain. Pain 1997; 73:213-221.

9. Schiottz-Christensen B, Nielsen GL, Hansen VK et al. Long-term prognosis of acute low back pain in patients seen in general practice: A 1-year prospective follow-up study. Fam Pract 1999; 16:223-232.

10. Ferguson SA, Marras WS, Gupta P. Longitudinal quantitative measures of the natural course of low back pain recovery. Spine 2000; 25:1950-1956.

11. Vingård $\mathrm{E}$, Mortimer $\mathrm{M}$, Wiktorin $\mathrm{C}$ et al. Seeking care for low back pain in the general population: A two-year follow-up study: Results from the MUSIC-Norrtalje Study. Spine 2002; 27:2159-2165.

12. Kuslich SD, Ulstrom CL, Michael CJ. The tissue origin of low back pain and sciatica: A report of pain response to tissue stimulation during operation on the lumbar spine using local anesthesia. Orthop Clin North Am 1991; 22:181-187.

13. Nachemson AL. Failed back surgery syndrome is syndrome of failed back surgeons. Pain Clinic 1999; 11:271-284.

14. Phillips FM, Cunningham B. Managing chronic pain of spinal origin after lumbar surgery. Spine 2002; 27:2547-2553.

15. Anderson SR. A rationale for the treatment algorithm of failed back surgery syndrome. Curr Rev Pain 2000; 4:395-406.

16. Slosar PJ. Indications and outcomes of reconstructive surgery in chronic pain of spinal origin. Spine 2002: 27:2555-2562.

17. Manchikanti L, Bakhit CE. Percutaneous lysis of epidural adhesions. Pain Physician 2000; 3:46-64. 
18. Fritsch EW, Heisel J, Rupp S. The failed back surgery syndrome. Reasons, intraoperative findings, and long-term results: $A$ report of 182 operative treatments. Spine 1996; 21:626-633.

19. Wilkinson HA. Introduction: Etiology, diagnosis, and therapy. In The Failed Back Syndrome. Etiology and therapy, Second Edition. Springer-Verlag, New York, 1992, pp 1-3.

20. Manchikanti L, Singh V. Epidural lysis of adhesions and myeloscopy. Curr Pain Headache Rep 2002; 6:427-435.

21. LaRocca H, Macnab I. The laminectomy membrane: Studies in its evolution, characteristics, effects and prophylaxis in dogs. J Bone Joint Surg 1974; 56:545550.

22. McCarron RF, Wimpee MW, Hudkins PG et al. The inflammatory effects of nucleus pulposus: A possible element in the pathogenesis of low back pain. Spine 1987; $12: 760-764$

23. McCarron RF. Epidural fibrosis: Experimental model and therapeutic alternatives. In Racz GB (ed). Techniques of Neurolysis. Kluwer Academic Publishers, Boston, 1989, pp 87-94.

24. Cooper RG, Freemont AJ, Hoyland JA et al. Herniated intervertebral disc-associated periradicular fibrosis and vascular abnormalities occur without inflammatory cell infiltration. Spine 1995; 20:591-598.

25. Hoyland JA, Freemont AJ, Jayson MI. Intervertebral foramen venous obstruction. A cause of periradicular fibrosis? Spine 1989; 14:558-568.

26. Parke WW, Watanable R. Adhesions of the ventral lumbar dura. Adjunct source of discogenic pain? Spine 1990; 15:300-303.

27. Rydevik BL. The effects of compression on the physiology of nerve roots. J Manipulative Physiol Ther 1992; 15:62-66.

28. Olmarker K, Rydevik B. Pathophysiology of spinal nerve roots as related to sciatica and disc herniation. In Herkowitz HN, Garfin SR et al (eds), Rothman-Simeone Studies, The Spine. WB Saunders, Philadelphia, 1999, pp 159-172.

29. Songer M, Ghosh L, Spencer D. Effects of sodium hyaluronate on peridural fibrosis after lumbar laminectomy and discectomy. Spine 1990; 15:550-554.

30. Pawl RP. Arachnoiditis and epidural fibrosis: The relationship to chronic pain. Curr Rev Pain 1998; 2:93-99.

31. Van Goethem JW, Van de Kelft E, Biltjes IG et al. MRI after successful lumbar discectomy. Neuroradiology 1996; 38:S90-S96.

32. Grane P, Tullberg T, Rydberg J et al. Postoperative lumbar magnetic resonance im- aging with contrast enhancement: Compression between symptomatic and asymptomatic patients. Acta Radiol 1996; 37:366-372.

33. Annertz M, Jönsson B, Stromqvist B et al. No relationship between epidural fibrosis and sciatica in the lumbar postdiscectomy syndrome: A study with contrast-enhancement magnetic resonance imagery in symptomatic and asymptomatic patients. Spine 1995; 20:449-453.

34. Cervellini P, Curri D, Volpin L et al. Computed tomography of epidural fibrosis after discectomy. A comparison between symptomatic and asymptomatic patients. Neurosurgery 1988; 6:710-713.

35. Benoist M, Ficat C, Baraf P et al. Post operative lumbar epiduroarachnoiditis: Diagnostic and therapeutic aspects. Spine 1980; 5:432-436.

36. Ross JS, Robertson JT, Frederickson RC et al. Association between peridural scar and recurrent radicular pain after lumbar discectomy: Magnetic resonance evaluation. Neurosurgery 1996; 38:855-863.

37. Manchikanti L, Staats P, Singh V et al. Evidence-based practice guidelines for interventional techniques in the management of chronic spinal pain. Pain Physician 2003; 6:3-80.

38. Revel M, Auleley GR, Alaoui S et al. Forceful epidural injections for the treatment of lumbosciatic pain with post-operative lumbar spinal fibrosis. Rev Rhum Engl Ed 1996; 63:270-277.

39. Meadeb J, Rozenberg S, Duquesnoy B et al. Forceful sacrococcygeal injections in the treatment of postdiscectomy sciatica. A controlled study versus glucocorticoid injections. Joint Bone Spine 2001; 68:4349.

40. Ciocon JO, Galindo-Ciocon D, Amaranath $L$ et al. Caudal epidural blocks for elderly patients with lumbar canal stenosis. J Am Geriatr Soc 1994; 42:593-596.

41. Fukusaki M, Kobayashi I, Hara $T$ et al. Symptoms of spinal stenosis do not improve after epidural steroid injection. Clin J Pain 1998; 14:148-151.

42. Heavner JE, Racz GB, Raj P. Percutaneous epidural neuroplasty. Prospective evaluation of $0.9 \% \mathrm{NaCl}$ versus $10 \% \mathrm{NaCl}$ with or without hyaluronidase. Reg Anesth Pain Med 1999; 24:202-207.

43. Manchikanti L, Pampati V, Fellows B et al. Role of one day epidural adhesiolysis in management of chronic low back pain: A randomized clinical trial. Pain Physician 2001; 4:153-166

44. Racz GB, Holubec JT. Lysis of adhesions in the epidural space. In Racz GB, editor.
Techniques of Neurolysis. Boston: Kluwer Academic, 1989, pp 57-72.

45. Manchikanti L, Pampati V, Rivera J et al Effectiveness of percutaneous adhesiolysis and hypertonic saline neurolysis in refractory spinal stenosis. Pain Physician 2001; 4:366-373

46. Manchikanti L, Pakanati R, Bakhit CE et al. Role of adhesiolysis and hypertonic saline neurolysis in management of low back pain. Evaluation of modification of Racz protocol. Pain Digest 1999; 9:91-96.

47. Manchikanti L, Pampati V, Bakhit CE et al. Non-endoscopic and endoscopic adhesiolysis in post lumbar laminectomy syndrome. A one-year outcome study and cost effective analysis. Pain Physician 1999; 2:52-58.

48. Hammer M, Doleys D, Chung O. Transforaminal ventral epidural adhesiolysis. Pain Physician 2001; 4: 273-279.

49. Manchikanti L, Saini B, Singh V. Spinal endoscopy and lysis of epidural adhesions in the management of chronic low back pain. Pain Physician 2001; 4:240-265.

50. Saberski L, Brull S. Spinal and epidural endoscopy: A historical review. Yale J Bio Med 1995; 68:7-15

51. Geurts JW, Kallewaard JW, Richardson J et al. Targeted methylprednisolone acetate/ hyaluronidase/clonidine injection after diagnostic epiduroscopy for chronic sciatica: A prospective, 1-year follow-up study. Reg Anesth Pain Med 2002; 27:343-352.

52. Richardson J, McGurgan P, Cheema $S$ et al. Spinal endoscopy in chronic low back pain with radiculopathy: A prospective case series. Anaesthesia 2001; 56:454-460.

53. Manchikanti L, Pampati V, Bakhit CE et al. Non-endoscopic and endoscopic adhesiolysis in post lumbar laminectomy syndrome. A one-year outcome study and cost effective analysis. Pain Physician 1999; 2:52-58.

54. Saberski L. A retrospective analysis of spinal canal endoscopy and laminectomy outcomes data. Pain Physician 2000; 3: 193-196.

55. Manchikanti L. The value and safety of epidural endoscopic adhesiolysis. Amer I Anesthesiol 2000; 275-278.

56. Krasuski P, Poniecka AW, Gal E et al. Epiduroscopy: Review of techniques and results. The Pain Clinic 2001; 13:71-76.

57. Waddell G, McCulloch JA, Kummel E et al. Nonorganic physical signs in low back pain. Spine 1980; 5:117-125.

58. Waddell G, Main CJ, Morris EW et al. Chronic low back pain, psychologic distress, and illness behavior. Spine 1984; 9: 209-213. 
